\title{
Effects of hygrothermal aging on chemical, physical, and mechanical properties of poly(3-hydroxybutyrate-co- 3-hydroxyvalerate)/Cloisite 30B bionanocomposite
}

\author{
Kahina Iggui ${ }^{1,2,3}$ \\ Mustapha Kaci ${ }^{1}$ \\ Nicolas Le Moigne ${ }^{3}$ \\ Anne Bergeret ${ }^{3}$
}

\begin{abstract}
${ }^{1}$ Laboratoire des Matériaux Polymères Avancés (LMPA), Université de Bejaia, Bejaia, Algeria

${ }^{2}$ Institut de Technologie, Université Akli Mohand Oulhadj, Bouira, Algeria

${ }^{3}$ Polymers Composites and Hybrids (PCH), IMT-Mines Ales, Ales, France

Correspondence

Kahina Iggui, Laboratoire des Matériaux Polymères Avancés (LMPA), Université de Bejaia, 06000, Algeria.

Email: iguikahina@yahoo.fr
\end{abstract}

\begin{abstract}
Hygrothermal aging of neat poly(3-hydroxybutyrate-co-3-hydroxyvalerate) (PHBV) and PHBV filled with an organomodified montmorillonite (C30B) at 3 wt. was investigated at $65^{\circ} \mathrm{C}$ and $100 \%$ relative humidity (RH) up to 100 days. FT-IR data indicated that the carbonyl intensity index decreased with exposure time for both samples, while the main degradation mechanism occurred through hydrolysis reaction. This led to chain scissions resulting in a decrease in molar mass. Water absorption increased with exposure time for both neat PHBV and PHBV/C30B (3wt\%) bionanocomposite. Differential scanning calorimetry measurements showed a decrease in both crystallinity index and melting temperature after hygrothermal aging and thermogravimetric analysis data indicated also a decrease in thermal stability. Mechanical and viscoelastic properties were also altered, being, however, more pronounced for the neat PHBV. Overall, the PHBV bionanocomposite exhibited a better resistance toward hygrothermal aging at $65^{\circ} \mathrm{C}$ and $100 \% \mathrm{RH}$.
\end{abstract}

\section{KE Y W O R D S}

bionanocomposite, chain scission, crystallinity, dynamic mechanical properties, hygrothermal aging, PHBV, thermal stability

\section{1 | INTRODUCTION}

Poly(3-hydroxybutyrate-co-3-hydroxyvalerate) (PHBV) is an aliphatic biopolyester of the polyhydroxyalkanoates (PHAs) family produced from a variety of bacteria ${ }^{[1-2]}$. Due to its biodegradability, biocompatibility and interesting physical properties, PHBV is an answer to nowadaysenvironmental issues and emerges in consumer markets, especially in food packaging and biomedical applications ${ }^{[3-4]}$. However, PHBV has limited mechanical and thermal properties, which restricts its use in other industrial fields ${ }^{[5]}$.

IMT-Mines Ales is member of the European Polysaccharide Network of Excellence (EPNOE), http://epnoe.eu/.
To overcome these drawbacks, the incorporation and dispersion of organomodified montmorillonite (OMMT) such as Cloisite 30B in PHBV could be an effective method to produce bionanocomposite materials with enhanced functional properties ${ }^{[6-8]}$. However, when exposed to environmental factors, such as temperature, humidity, UV light etc., PHBV undergoes aging and degradation ${ }^{[9-10]}$. In this regard, hygrothermal aging combines the effects of both humidity and temperature, which often result in irreversible changes in the chemical structure, molar mass and physical properties of the polymer materials ${ }^{[11-12]}$. According to the literature ${ }^{[13-15]}$, in hygrothermal aging, polyesters undergo an auto-catalytic random chain scission and ester bond hydrolysis is the main degradation mechanism ${ }^{[16-18]}$. The hydrolysis 
process can be sensitive to humidity, temperature, and environmental pressure ${ }^{[19-20]}$. Generally, it is accelerated by the synergic effect of temperature and high humidity content ${ }^{[21]}$.

Several studies dealt with the hygrothermal behavior of different PHAs, mainly involving their blends and biocomposites reinforced with (ligno)-cellulosic fibers. In this topic, Zhuikov et al. ${ }^{[22]}$ studied the hydrolytic degradation of biopolyester poly-3-hydroxybutyrate (PHB) films with different molecular weights and different content ratios of 3-hydroxyvalerate(3-HV) with and without polyethylene glycol (PEG) used as the compatibilizer. The degradation of PHAs films was carried out in saline solution of phosphate-buffered saline (PBS) at $37^{\circ} \mathrm{C}$ and $\mathrm{pH}$ of 7.4 for 187 days. The authors reported that the total mass of (PHB-3HV) copolymer films with high-molecular weight and $17.6 \%$ and $9 \%$ of 3-hydroxyvalerate slightly decreased up to $8 \%-9 \%$. Conversely, no significant changes were observed for the other samples even after 180 days. Hydrophobic character of all samples decreased after hydrolytic degradation, with a decrease in water contact angle by almost $17 \%$. More recently, Mazur and Kuciel ${ }^{[23]}$ in their study on PHBV and wood fibers biocomposites filled at 7.5 and $15 \mathrm{wt} \%$ exposed to hydrothermal aging in saline solution at $40^{\circ} \mathrm{C}$, showed that the water absorption rate increased logically with fiber content ratio; the highest rate was observed for the biocomposite filled at $15 \mathrm{wt} \%$. After 2 weeks of aging, the tensile strength decreased slightly by almost $10 \%$ for the PHBV/wood fibers (15wt\%) compared with that of the unexposed sample. Marinho et al. ${ }^{[24]}$ studied the effect of water absorption on the performance of $\mathrm{PHB} /$ babassu fibers biocomposites loaded at different filler content ratios, that is, 5,10 , and $20 \mathrm{wt} \%$. The authors concluded that the absorption process became slower as the fiber content increased. Water diffusion coefficient of PHB/babassu composite (20wt\%) was about $4 \times 10^{-8} \mathrm{~cm}^{2} \mathrm{~s}^{-1}$. The elastic modulus calculated at saturation decreased by $10 \%-30 \%$ with respect to fiber content, but tensile strength and elongation at break remained almost unchanged. Badia et al. ${ }^{[25]}$ studied the hydrothermal stability of PHBV/sisal fibers biocomposites at three temperatures 26,36 , and $46^{\circ} \mathrm{C}$. The authors noticed that the effect of both temperature and percentage of fibers induced an increase of water diffusion rate. However, the water uptake was only affected by the fiber content. Also the mechanical properties of the biocomposites were altered; because the swelling of fibers induced cracks within the polymer as well as interfacial decohesion with the fibers. Ventura et al. ${ }^{[26]}$ also reported that moisture uptake can induce microcracks at the fiber-matrix interface with matrix damage and interfacial decohesion in PHB biocomposites reinforced with flax fibers. On the other hand, the incorporation of clays can affect the inherent hydrophilicity of polyesters which in turn has an effect on the whole degradation mechanism. Silva et al. ${ }^{[27]}$ investigated hydrolytic degradation of PHB, PEG, and organophilic vermiculite (VMT) clay bionanocomposites (PHB/PEG/VMT) at $95 / 5 / 3 \mathrm{wt} \%$ in saline solution at $37^{\circ} \mathrm{C}$ and $\mathrm{pH}=7.4$. They observed that the addition of the VMT clay led to a mass loss of about $5 \%$ in the fourth week of hydrolytic degradation and decreased the crystallinity. FT-IR results indicated that the occurrence of degradation process of pure PHB in the amorphous phases and was accelerated by the addition of reinforcement and compatibilizer agent, leading to increase of carbonyl index. Studies on degradation of $\mathrm{PHBV} /$ clays bionanocomposites under hygrothermal conditions have not been sufficiently addressed in the open literature. Therefore, further investigations are necessary to better understanding the effect of organo-modified montmorillonite on hydrolytic degradation of PHBV and its physical properties so as to better predict the material service life.

In this regard, the objective of the present work was to study the effect of hygrothermal aging on the chemical structure, the physical and the mechanical properties of neat PHBV and PHBV/OMMT bionanocomposite (3wt\%) at $65^{\circ} \mathrm{C}$ and $100 \%$ HR in autoclave. Structural changes were investigated by FT-IR spectroscopy and size-exclusion chromatography (SEC) analysis. Thermal properties were determined by differential scanning calorimetry (DSC), while thermal stability was evaluated by thermogravimetric analysis (TGA). Tensile properties and viscoelastic properties were also determined. The morphological defects due to hygrothermal degradation were characterized by scanning electron microscopy (SEM) observations.

\section{2 | EXPERIMENTAL METHODS}

\section{1 | Materials used and sample preparation}

PHBV (PHI $002^{\circledR}$ ) was commercialized by Nature Plast (France). The commercial organomodified Cloisite 30B (C30B) was purchased from Southern Clay Products, Inc. (USA).

PHBV and nanobiocomposite films samples of $500 \mu \mathrm{m}$ thickness, named Cast PHBV and CPHBV/3C30B (3wt\%), respectively, were melt blended using a single-screw cast extruder by masterbatch dilution with neat PHBV of a PHBV/C30B mixture prepared by twin-screw extrusion. The preparation method of the masterbatch and films has been previously detailed in recent paper ${ }^{[28]}$. ISO $1 / 2$ dumbbell specimens were cut from PHBV and bionanocomposite films. 


\section{2 | Hygrothermal aging}

Hygrothermal aging has been recorded in a stainless steel autoclave (SANOCLAV) at atmospheric pressure, $100 \%$ $\mathrm{RH}$ and $65^{\circ} \mathrm{C}$ up to 100 days ${ }^{[29]}$. Films of Cast PHBV and PHBV/3C30B bionanocomposite samples were vertically positioned above the distilled water surface. Aged specimens were collected periodically and dried in a vacuum oven at $60^{\circ} \mathrm{C}$ for $24 \mathrm{~h}$. Finally the specimens were stored in vacuum chamber at ambient temperature and $2 \% \mathrm{RH}$ for the subsequent chemical, physical, and mechanical characterizations.

\section{3 | Characterization methods}

\subsection{1 | Water absorption}

Weight gains of Cast-dried PHBV and dried C-PHBV/3C30B at $60^{\circ} \mathrm{C}$ in a vacuum oven during $24 \mathrm{~h}$ were measured by a gravimetric method. This method consists of removing at regular intervals the samples from an autoclave and weighing them with digital analytical balance. Five samples of each material were periodically removed from water, wiped and weighed. The weight gain $M(t)$ as a result of water absorption, was determined according to Equation (1):

$$
M(t)=\frac{W(t)-W d}{W d}
$$

where $W d$ and $W(t)$ correspond, respectively, to the weight of sample (the initial weight of dried sample before exposure to water absorption) and to the weight of the sample after a time $t$ of exposure to water absorption. The water diffusion coefficient $D$ was determined according to Fick's law and using Equation (2) adapted for long-time approximation ${ }^{[30]}$, that is, $0.4<\frac{M(t)}{M_{\infty}}<1$ :

$$
\frac{M(t)}{M_{\infty}}=1-\frac{8}{\pi^{2}} \exp \left(\frac{-D \pi^{2}}{e^{2}} t\right)
$$

where $M_{\infty}$ is the weight gain at infinite time and $e$ is half of the sample thickness, that is, $250 \mu \mathrm{m}$, because diffusion takes place from both sides.

\subsection{2 | Size-exclusion chromatography (SEC)}

SEC analysis was carried out by an Omni-SECT 60A system equipped with a Waters 410 differential refractometer. SEC analysis was conducted on neat PHBV,
Cast PHBV, and C-PHBV/3C30B bionanocomposite in a PL Gel $5-\mathrm{mm}$ Mixed-C column $(1 \times 600 \mathrm{~mm})$. The chloroform was used as an eluent with a flow rate of $1 \mathrm{ml} \mathrm{min}{ }^{-1}$. Before injection, approximately $20 \mathrm{mg}$ of each material were dissolved in $2 \mathrm{ml}$ of chloroform over $1 \mathrm{~h}$ at $60^{\circ} \mathrm{C}$. To remove any insoluble fractions or nanofiller, the solutions were filtered through a Phenex PTFE $0.2 \mathrm{~mm}$ filter. For calibration polystyrene standards were used. The average results of two tests of each sample were reported.

\subsection{3 | Solubility test}

In order to check whether there is the formation of gel fraction during hydrothermal aging, solubility tests were conducted by a Soxhlet apparatus. One gram of exposed and unexposed Cast PHBV and C-PHBV/3C30B bionanocomposite dried samples were dissolved in $100 \mathrm{ml}$ of chloroform at $60^{\circ} \mathrm{C}$ for $1 \mathrm{~h}^{[31]}$.

\subsection{4 | Fourier transform infrared spectroscopy (FT-IR)}

FT-IR spectra of Cast PHBV and C-PHBV/3C 30B bionanocomposite dried samples were performed on a BRUKER Vertex 70 spectrometer. The attenuated total reflectance (ATR) measurements were recorded for each material at a resolution of $4 \mathrm{~cm}^{-1}$ and 32 scans from $4000-400 \mathrm{~cm}^{-1}$.

\subsection{5 | Differential scanning calorimetry (DSC)}

A DSC analysis was carried out by a Pyris Diamond DSC thermal analysis system (PerkinElmer) using nitrogen as inert gas. Dried samples (15-20 mg) were sealed into aluminum pans and heating-cooling-heating was carried out in the temperature range starting from 30 to $200^{\circ} \mathrm{C}$ at a heating rate of $10^{\circ} \mathrm{C} \mathrm{min}^{-1}$. The crystallinity index $\left(X_{\mathrm{c}}\right)$ was calculated using Equation (3):

$$
X_{\mathrm{c}}=\frac{\Delta H_{m}}{W \cdot \Delta H_{m}^{0}} \times 100
$$

where $\Delta H_{\mathrm{m}}\left(\mathrm{J} . \mathrm{g}^{-1}\right)$ is the melting enthalpy, $\Delta H_{m}^{0}$ is the melting enthalpy of $100 \%$ crystalline $\operatorname{PHBV}\left(\Delta H_{m}^{0}\right.$ $\left.=146 \mathrm{~J}^{-g^{-1}}{ }^{[32]}\right)$ and $W$ is the weight fraction of PHBV in the bionanocomposite sample. Three replicates were tested for each sample. 

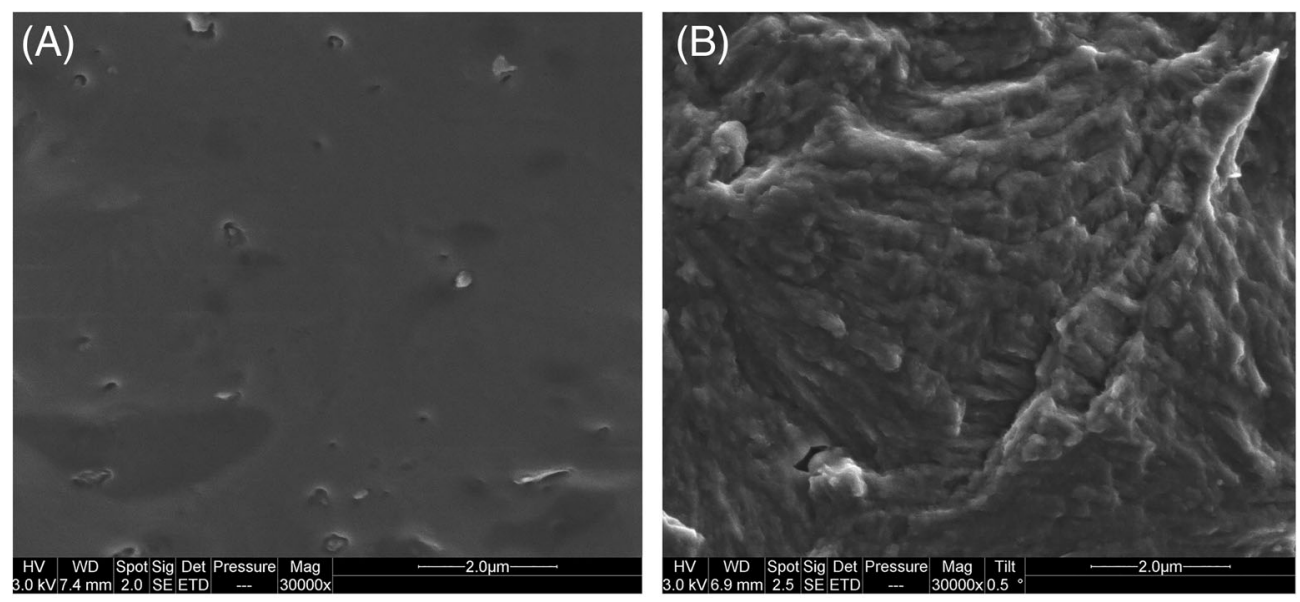

FIGURE 1 SEM images of fractured surface of Cast PHBV (A) before exposure (B) after 100 days of exposure and C-PHBV/3C30B

bionanocomposite (C) before exposure and (D) after 100 days of exposure. SEM, scanning electron microscopy; PHBV, poly(3-hydroxybutyrate-co3-hydroxyvalerate)
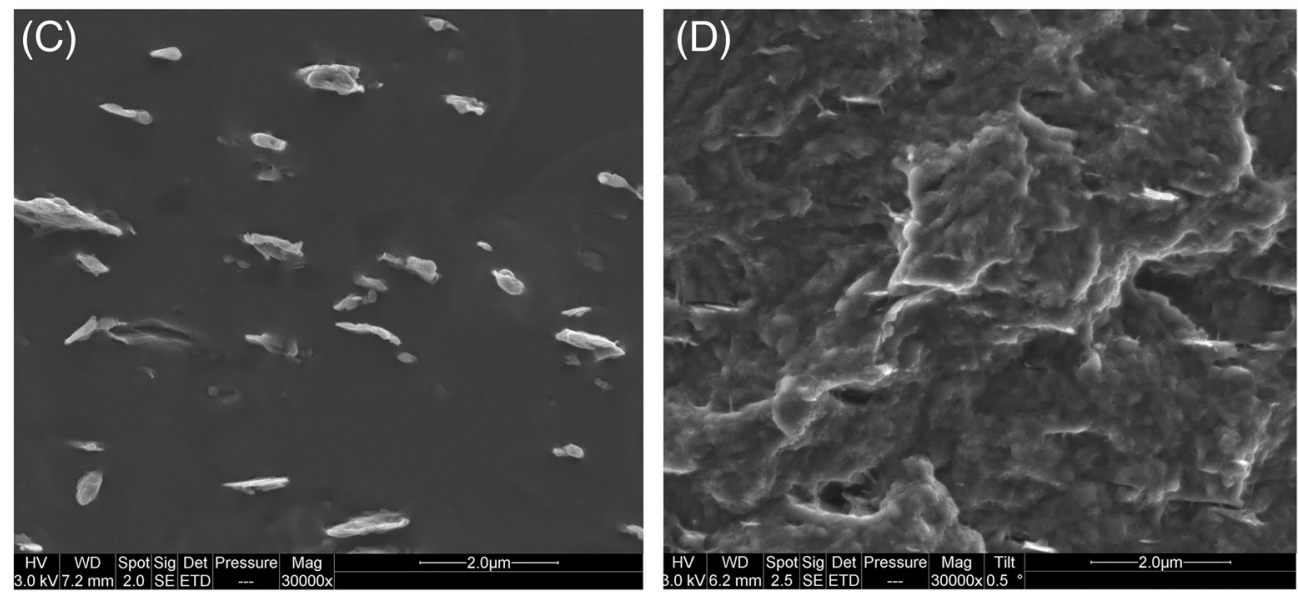

\begin{tabular}{lcccc} 
Samples & Exposure time (days) & $\overline{\boldsymbol{M}}_{\boldsymbol{w}}\left(\frac{\mathrm{g}}{\mathrm{mol}}\right)$ & $\overline{\boldsymbol{M}}_{\boldsymbol{n}}\left(\frac{\mathrm{g}}{\mathrm{mol}}\right)$ & Ð \\
\hline Neat PHBV & \multicolumn{1}{c}{} & 375,835 & 121,747 & 3.09 \\
\hline Cast PHBV & 0 & 290,860 & 112,950 & 2.6 \\
& 30 & 105,299 & 46,680 & 2.3 \\
& 100 & 46,380 & 21,886 & 2.1 \\
\hline C-PHBV/3C30B & 0 & 305,510 & 94,640 & 3.2 \\
& 30 & 138,603 & 64,573 & 2.2 \\
& 100 & 51,768 & 23,995 & 2.1 \\
\hline
\end{tabular}

TABLE 1 Values of $\overline{\boldsymbol{M}}_{\boldsymbol{w}}, \overline{\boldsymbol{M}}_{n}$ and $\boldsymbol{Ð}$ of neat PHBV, Cast PHBV, and C$\mathrm{PHBV} / 3 \mathrm{C} 30 \mathrm{~B}$ bionanocomposite as function of exposure time

Abbreviation: PHBV, poly(3-hydroxybutyrate-co-3-hydroxyvalerate).

\subsection{6 | Thermogravimetric analysis (TGA-DTG)}

Thermal stability of aged samples was evaluated by thermogravimetric analysis under nitrogen atmosphere. TGA-DTG thermograms were recorded with a Pyris Diamond thermogravimetric analyzer (PerkinElmer). Dried samples of an average weight of 10-12 mg were heated from 30 to $700^{\circ} \mathrm{C}$, at a heating rate of $10^{\circ} \mathrm{C} \mathrm{min}{ }^{-1}$. Three replicates were tested for each sample.

\subsection{7 | Dynamic mechanical analysis}

The viscoelastic properties of aged samples were determined by DMA 50 dynamic mechanical analyzer (Metravib O3dB, France), under standard ISO 6721-10. The rectangular samples with a dimension of $35 \times 5 \times 0.5 \mathrm{~mm}$ were subjected to deformation in shear mode at $5 \mu \mathrm{m}$ of amplitude and $5 \mathrm{~Hz}$, in temperature range from -20 to $120^{\circ} \mathrm{C}$ at a heating rate of $3{ }^{\circ} \mathrm{C} \min ^{-1}$. 

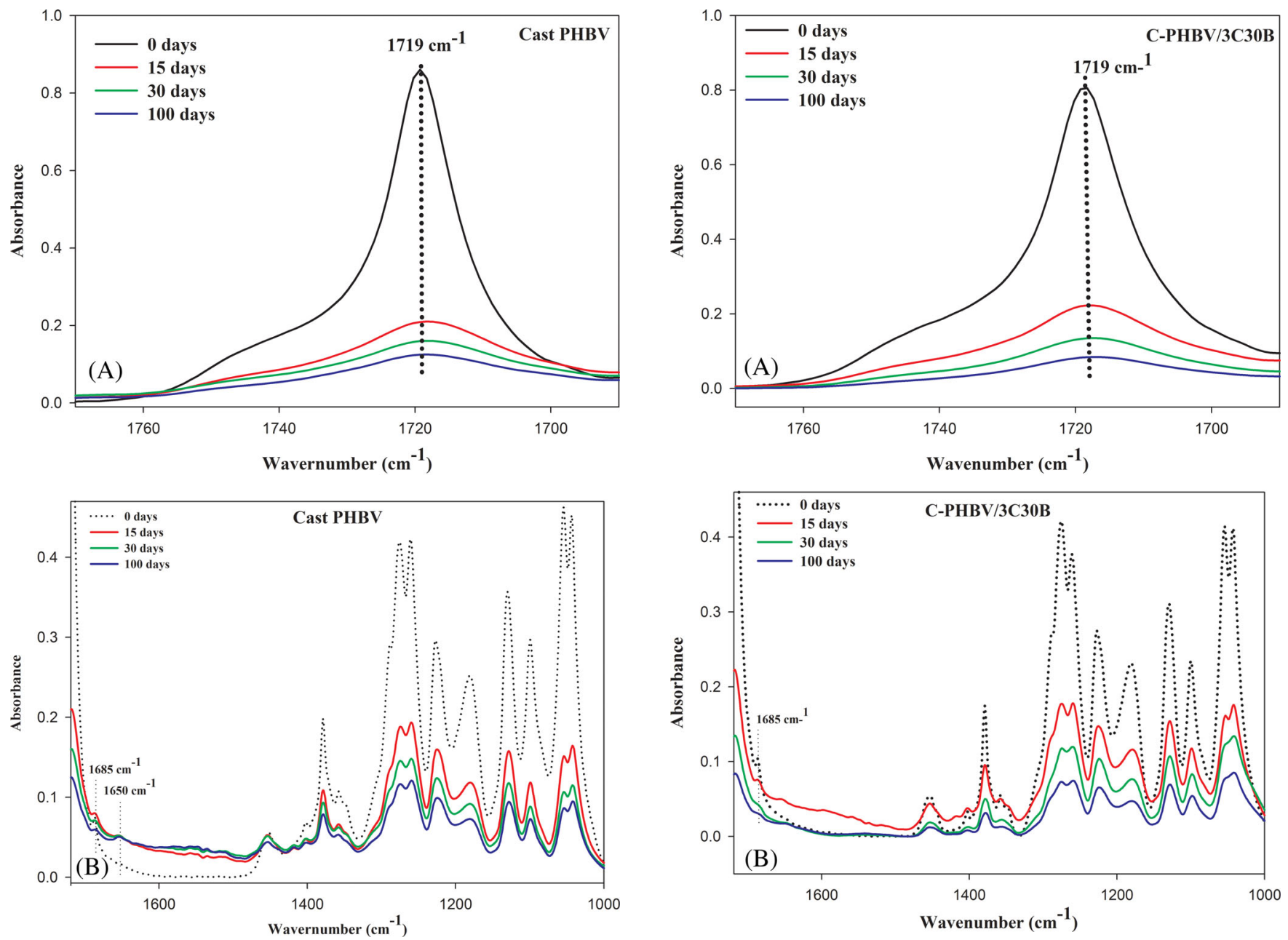

F I G U RE 2 FT-IR spectra of Cast PHBV before and after exposure to hygrothermal aging recorded in the carbonyl region: (A) $1760-1700 \mathrm{~cm}^{-1}$ and (B) $1600-1000 \mathrm{~cm}^{-1}$. PHBV, poly (3-hydroxybutyrate-co-3-hydroxyvalerate) [Color figure can be viewed at wileyonlinelibrary.com]

\subsection{8 | Tensile testing}

The tensile properties of aged samples were performed by Zwick/Roell machine according to ISO 527 standard procedure. Young's modulus was measured at a cross-head speed of $1 \mathrm{~mm} \mathrm{m^{-1 }}$ using an incremental clip-on extensometer (Zwick/Roell). The tensile strength and elongation at break were determined at a speed of $50 \mathrm{~mm} \mathrm{~min}{ }^{-1}$. Five specimens of each dried material were tested.

\subsection{9 | Scanning electron microscopy}

SEM was performed to examine the fractured surface of samples before and after exposure to hygrothermal aging. The microscopic observations were made in

environmental mode using a Quanta 200 FEG (FEI Company) scanning electron microscope. Prior to observations, the fracture surfaces of the films were sputter coated with carbon by evaporator apparatus (Balzers).

\section{3 | RESULTS AND DISCUSSION}

\section{1 | SEM observations}

SEM images of the fractured surface of unexposed and exposed films to hygrothermal aging are illustrated in Figure 1(A)-(D). From Figure 1(A), the SEM micrograph of Cast PHBV before exposure, exhibits a smooth surface in which some black particles in circular form of boron nitride are observed, incorporated as nucleating agent in PHBV matrix. The bionanocomposite sample exhibits the 
same surface morphology as the neat polymer (see Figure 1(C)) with however, the presence of some clay tactoids in the PHBV matrix of different size and shape. In previous work ${ }^{[28]}$, Wide angle X-ray diffraction (WAXD) and morphological data by Scanning transmission electron microscopy (STEM) showed that the PHBV/3C30B bionanocomposite exhibits an intercalated structure. After 100 days of exposure to hygrothermal aging, the fracture surface of aged samples shows considerable changes as the appearance of cracks and voids clearly observable in Figure 1(B) and (D).

\section{2 | Molecular weight changes}

SEC data of unexposed and exposed samples to hygrothermal aging are shown in Table 1 . Reduction of about $23 \%$ in $\bar{M}_{w}$, $7 \%$ in $\bar{M}_{n}$, and $16 \%$ in $\mathbf{Ð}$ are observed between neat and Cast PHBV. This is attributed to thermal degradation of matrix polymer during melt processing. From Table 1, after hygrothermal aging, the data show that the values of $\left(\bar{M}_{\mathrm{w}}\right)$ and $\left(\bar{M}_{\mathrm{n}}\right)$ of both samples are reduced with increasing exposure time. Indeed, after 30 days, there is a decrease in $\left(\bar{M}_{\mathrm{w}}\right)$ by roughly 2.5 times for Cast PHBV and 2 times for the PHBV bionanocomposite compared with the unexposed samples. Up to 100 days of exposure, the percent decrease in both $\left(\bar{M}_{\mathrm{W}}\right)$ and $\left(\bar{M}_{\mathrm{n}}\right)$ is almost $84 \%$ and $81 \%$ for Cast PHBV and 83 and $75 \%$ for CPHBV/3C30B bionanocomposite, respectively. However, there is no change in the value of polydispersity index (Đ) after exposure. This indicates the prevalence of chains scission mechanism, which is responsible for the materials degradation. Furthermore, the results of solubility test corroborate with those obtained by SEC showing no X-linking formation in the aged samples. Similar result was observed in previous studies ${ }^{[33-34]}$ dealing with accelerated photooxidation and gamma irradiation of $\mathrm{PHBV} / 3 \mathrm{C} 30 \mathrm{~B}$ bionanocomposite. According to Deroiné et al. ${ }^{[35]}$, chain breakage and ester bond hydrolysis are the main reactions occurring during the degradation of PHAs. It was, however, observed that the average number of chain scissions of C-PHBV/3C30B bionanocomposite is lower than that of Cast PHBV. This phenomenon could be due probably to the addition of C30B in PHBV, which slows down the hydrolytic kinetics of the bionanocomposite sample.

\section{3 | Chemical structure changes}

Chemical structure changes due to hygrothermal aging of aged samples were evaluated by FT-IR analysis. Representative absorbance spectra in the carbonyl region are
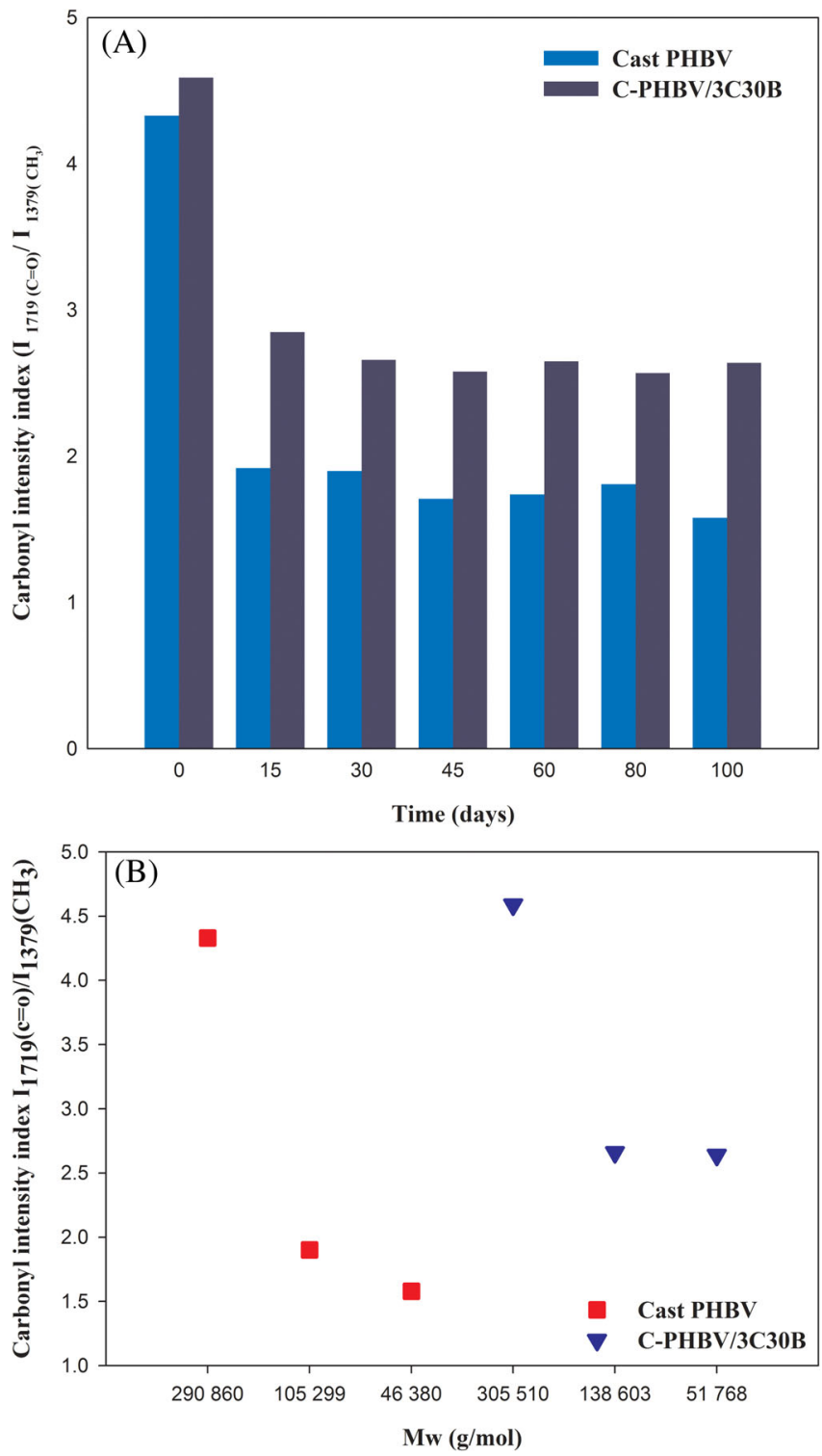

F I G U RE 4 Evolution of carbonyl intensity index with exposure time to hygrothermal aging (A) and molecular weight (B) for Cast PHBV and C-PHBV/3C30B. PHBV, poly (3-hydroxybutyrate-co-3-hydroxyvalerate) [Color figure can be viewed at wileyonlinelibrary.com]

shown in Figures 2(A), (B) and 3(A), (B). In Figure 2(A), relative to unexposed Cast PHBV, FT-IR spectra shows a strong band centered at $1719 \mathrm{~cm}^{-1}$, assigned to ester groups. After exposure, the absorption band intensity strongly decreases with exposure time. This results from hydrolysis reactions involving the ester groups of PHBV and hydroxyl groups of moisture leading to changes in chemical structure of aged samples. Similar trend was observed by Badia et al. ${ }^{[25]}$ for PHBV and PHBV/sisal biocomposite under hydrothermal aging. The authors attributed this phenomenon to hydrolytic degradation, resulting in chain scission, which is in a good agreement 
FIG URE 5 Evolution of water absorption of Cast PHBV and $\mathrm{C}-\mathrm{PHBV} / 3 \mathrm{C} 30 \mathrm{~B}$

bionanocomposite with exposure time in hygrothermal aging (100\% RH, $\left.65^{\circ} \mathrm{C}\right)$. PHBV, poly(3-hydroxybutyrate-co3-hydroxyvalerate) [Color figure can be viewed at wileyonlinelibrary.com]

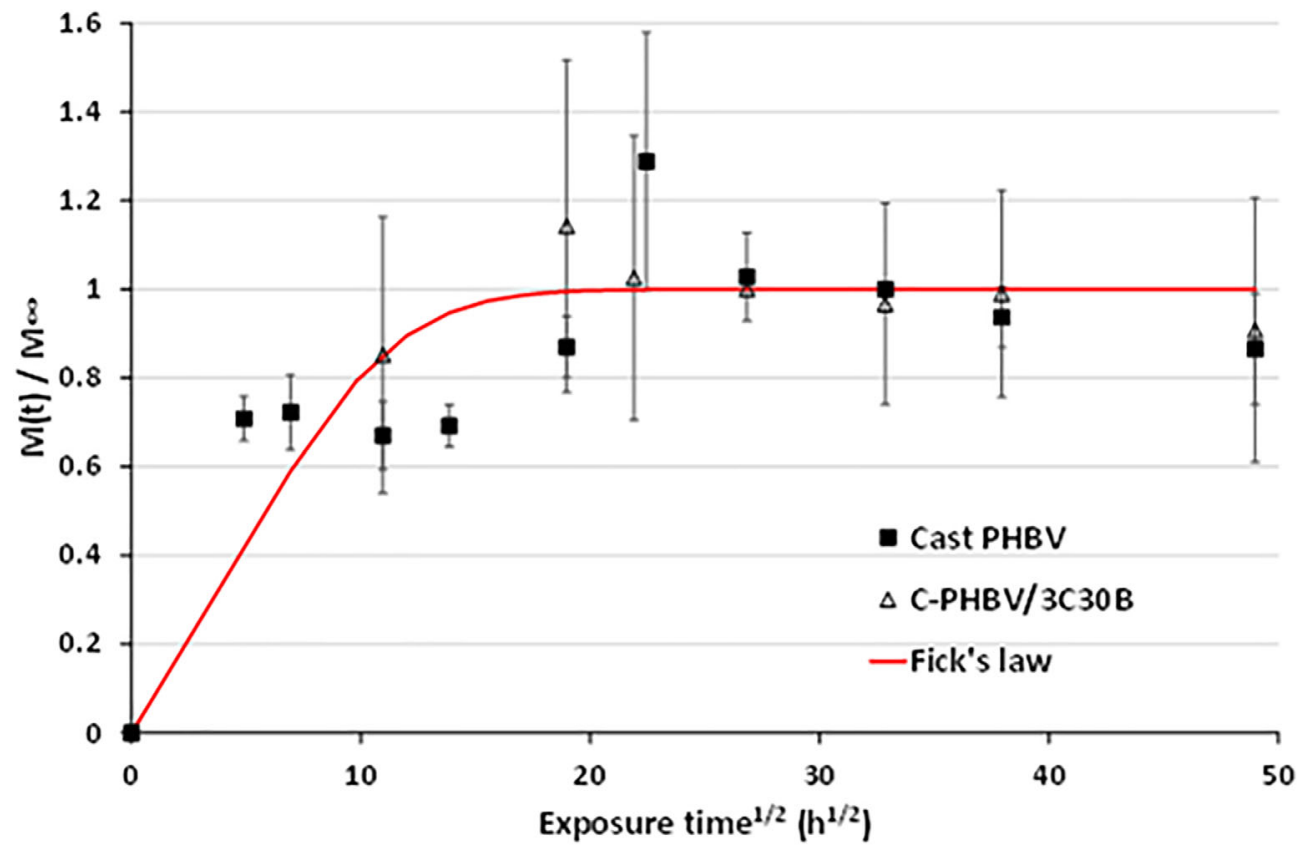

T A B L E 2 Evolution of thermal characteristics of neat PHBV, Cast PHBV, and C-PHBV/3C30B bionanocomposite before and after exposure to hygrothermal aging $\left(100 \% \mathrm{RH}, 65^{\circ} \mathrm{C}\right)$

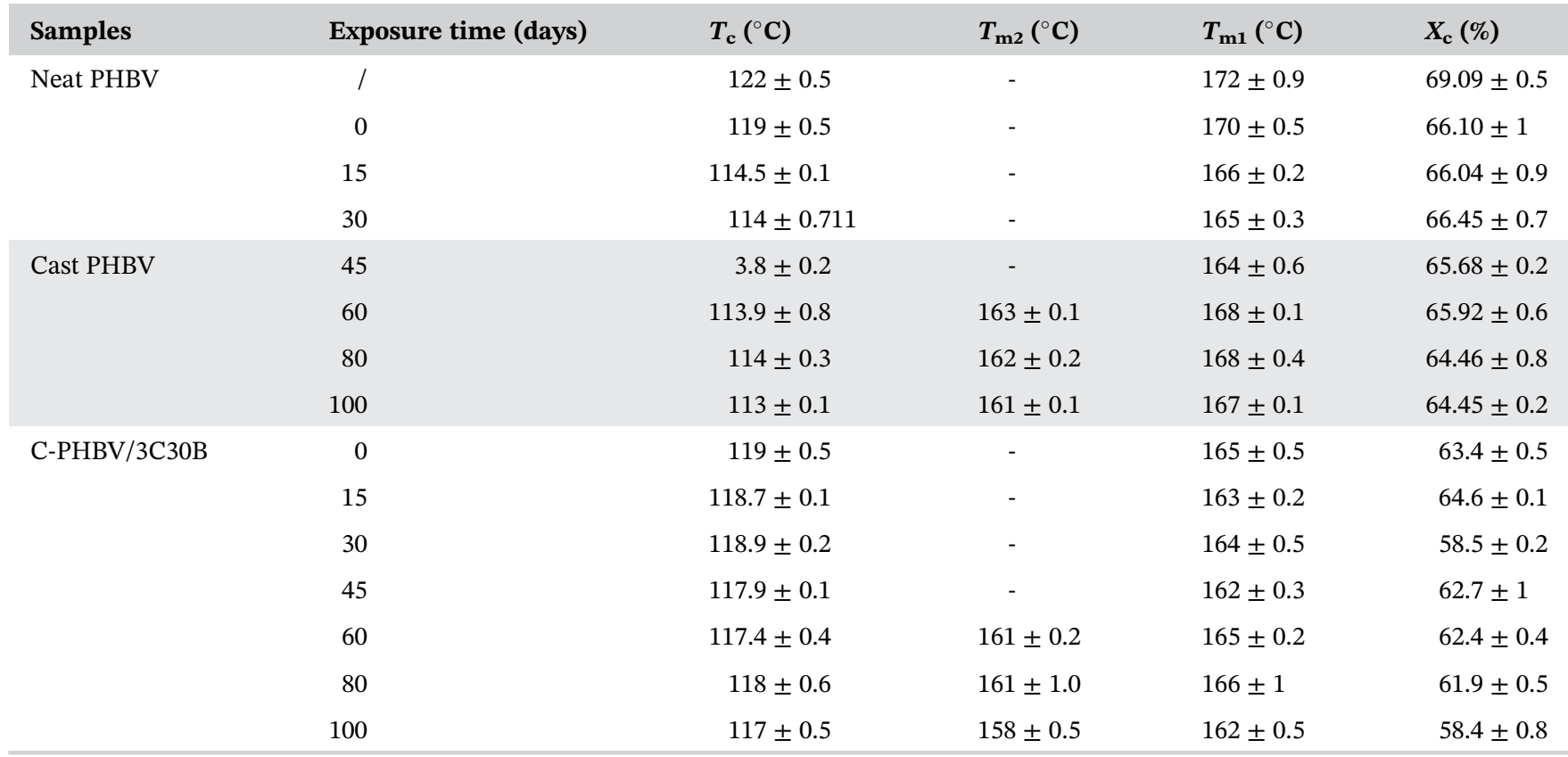

Abbreviations: PHBV, poly(3-hydroxybutyrate-co-3-hydroxyvalerate); RH, relative humidity.

with SEC data. Zembouai et al. ${ }^{[36-37]}$ reported also same behavior on the radiolytic degradation of PHBV. In the region of $1600-1000 \mathrm{~cm}^{-1}$, Figure 2 (B) shows a significant change in the chemical structure of the aged specimens. Indeed, FT-IR spectra of Cast PHBV show that the absorption band intensity located at $\lambda_{\max }=1685 \mathrm{~cm}^{-1}$ assigned to $\mathrm{C}=\mathrm{O}$ groups decreases with exposure time. It is also observed that the band intensity located at $\lambda_{\max }=1053$ and $1043 \mathrm{~cm}^{-1}$, attributed to C-O groups, are inversed. The formation of a short absorption band located at $\lambda_{\max }=1650 \mathrm{~cm}^{-1}$ results from the hydrolysis of ester groups of PHBV leading to formation hydroxyl groups.

The FT-IR spectra of C-PHBV/3C30B bionanocomposite (Figure 3(A), (B)) are almost similar to those of the Cast PHBV. This suggests that the presence of C30B organoclay does not affect the mechanism of hydrolytic degradation of PHBV. 

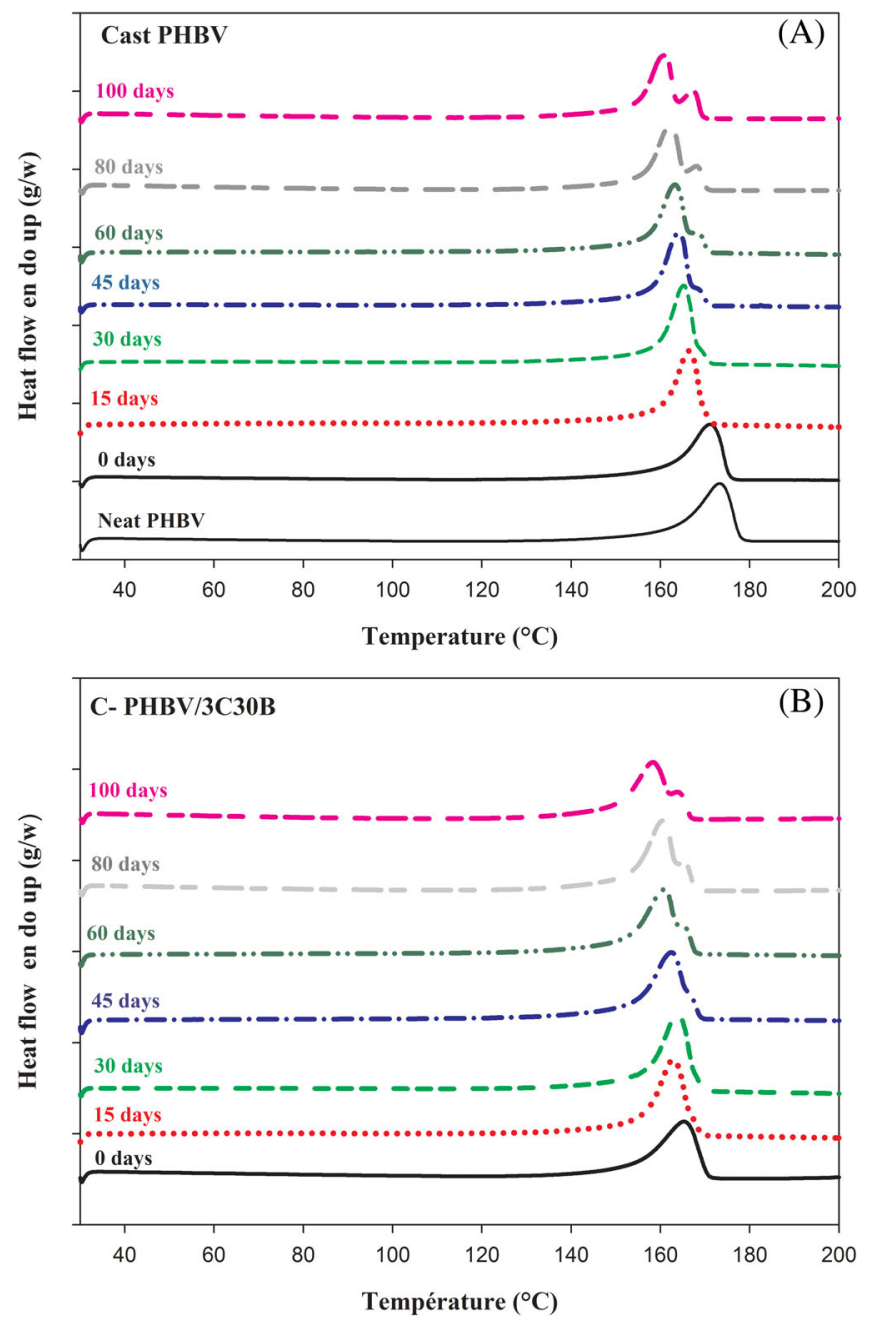

F I G U RE 6 DSC thermograms of (A) neat PHBV, Cast PHBV and (B) C-PHBV/3C30B bionanocomposite as a function of exposure time in hygrothermal aging $\left(100 \% \mathrm{RH}, 65^{\circ} \mathrm{C}\right)$. PHBV, poly (3-hydroxybutyrate-co-3-hydroxyvalerate) [Color figure can be viewed at wileyonlinelibrary.com]

The determination of the carbonyl intensity index is a usual method to evaluate the level of hydrolytic degradation of polymers. Carbonyl intensity index is defined as the ratio of the absorption band intensity at $1719 \mathrm{~cm}^{-1}$ $(\mathrm{C}=\mathrm{O}) / 1379 \mathrm{~cm}^{-1}\left(\mathrm{CH}_{3}\right)^{[25]}$, which remains unchanged during hygrothermal aging for both Cast PHBV and CPHBV/3C30B bionanocomposite.

The absorption band at $1379 \mathrm{~cm}^{-1}$ which corresponds to the $\mathrm{CH}_{3}$ asymmetric groups is used as reference and it is useful for normalizing thickness or sample positioning. The results are shown in Figure 4(A). A general decrease of carbonyl intensity index is observed with increasing the exposure time. Furthermore, it is noted that at initial stage of exposure (30 days), both samples already exhibit a rapid decrease in the carbonyl intensity index. Above 45 days of exposure, the carbonyl intensity index is not more affected and remains higher for C-PHBV/3C30B bionanocomposite. This is
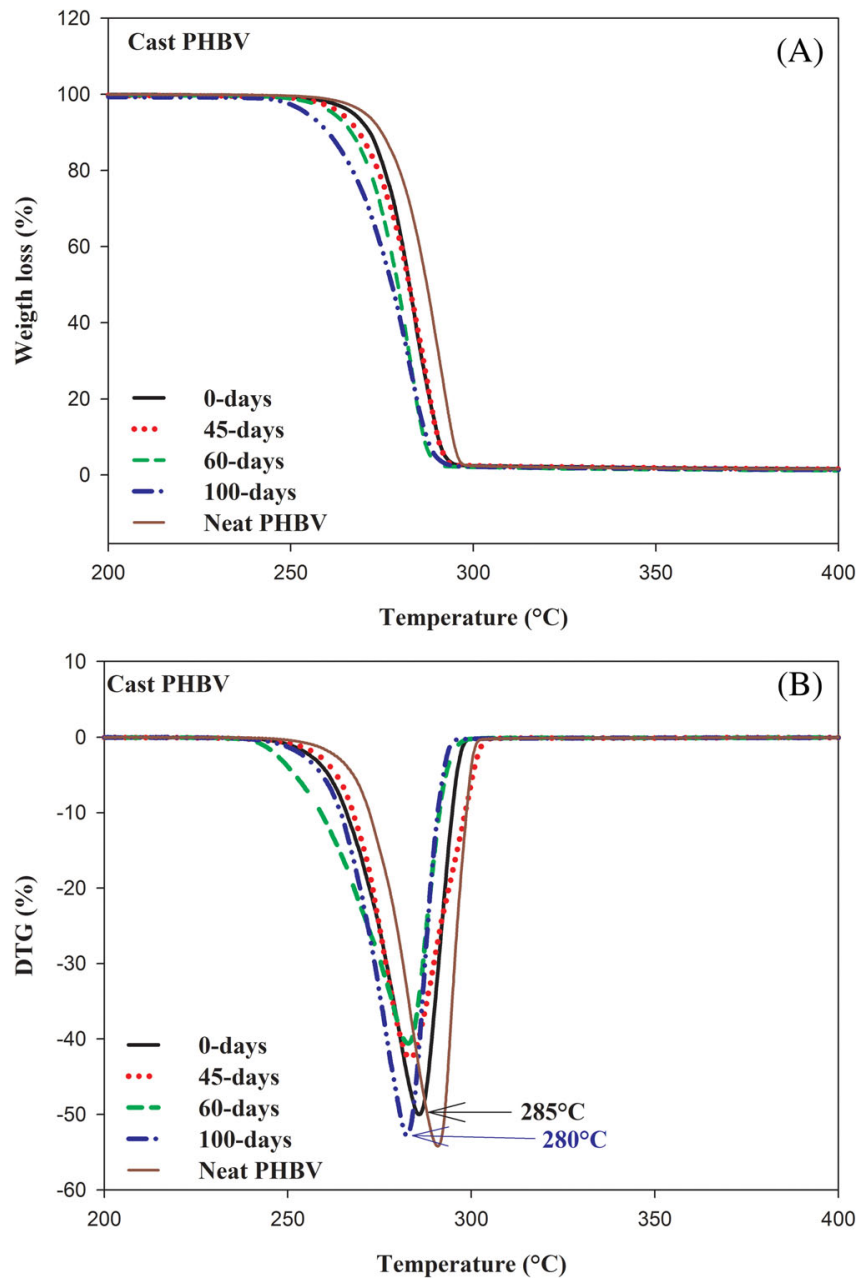

F I G U RE 7 (A) TGA and (B) DTG curves of neat PHBV, Cast PHBV before and after exposure to hygrothermal aging (100\% $\mathrm{RH}$, $65^{\circ} \mathrm{C}$ ). PHBV, poly(3-hydroxybutyrate-co-3-hydroxyvalerate); TGA, thermogravimetric analysis [Color figure can be viewed at wileyonlinelibrary.com]

consistent with the SEC data. Indeed, the plots in Figure 4(B) display similar trend for both the carbonyl intensity index and molecular weight, that is, the carbonyl intensity index decreases with decreasing the molecular weight.

\section{4 | Water absorption}

Figure 5 shows the curves of water absorption as a function of exposure time for Cast PHBV and C-PHBV/3C30B bionanocomposite. It is observed that the water absorption plots exhibit similar trend for both samples and a quasi-plateau of roughly $1080 \mathrm{~h}$ (45 days) and $720 \mathrm{~h}$ (30 days) for Cast PHBV matrix and C-PHBV/3C30B bionanocomposite, respectively. At this stage, the water absorption value (Equation 1) is $0.98 \%$ for Cast PHBV and $1.90 \%$ for C-PHBV/3C30B. Experimental data show a Fickian's behavior, characterized by a linear relationship 

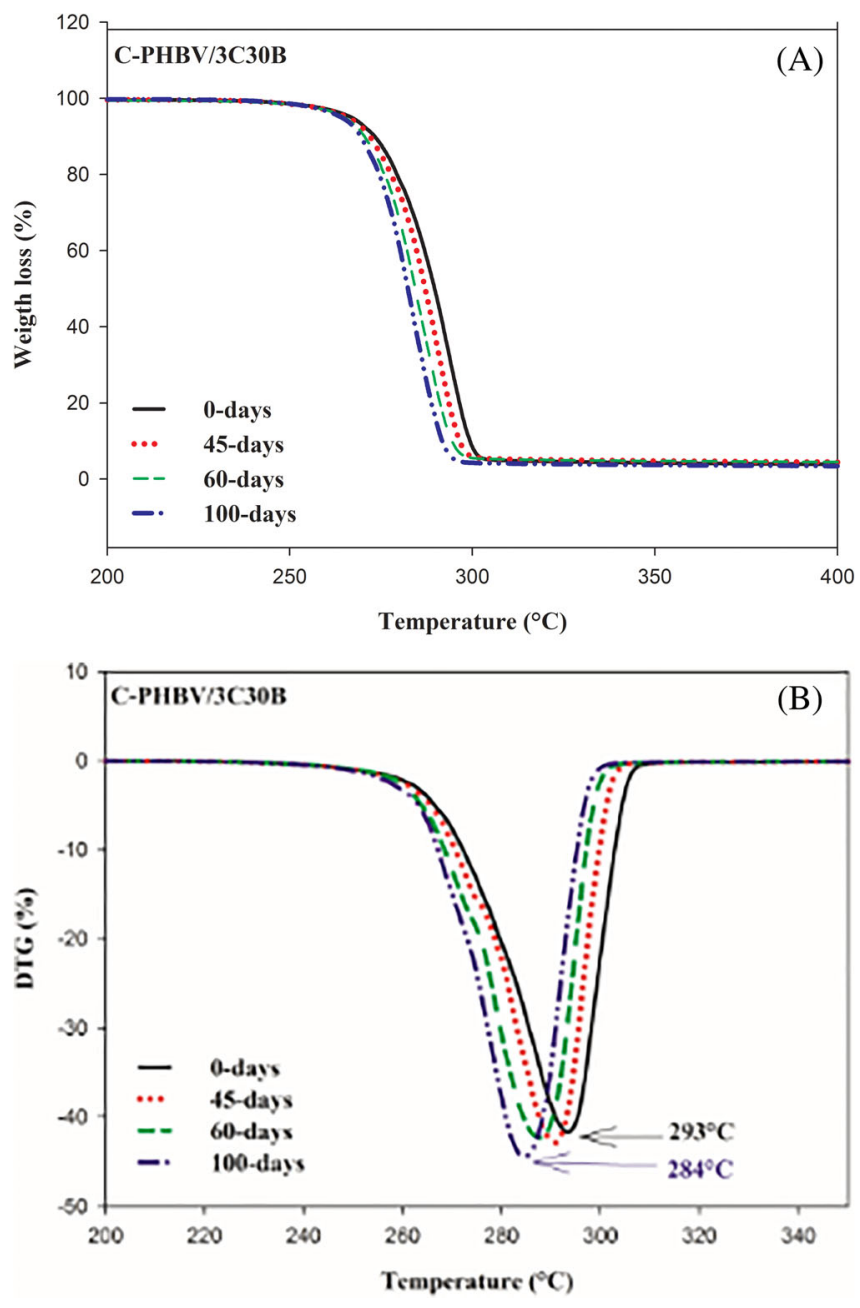

F I G U RE 8 Thermograms (A) TGA and (B) DTG of C$\mathrm{PHBV} / 3 \mathrm{C} 30 \mathrm{~B}$ bionanocomposite before and after exposure to hygrothermal aging $\left(100 \% \mathrm{RH}, 65^{\circ} \mathrm{C}\right)$. PHBV, poly

(3-hydroxybutyrate-co-3-hydroxyvalerate); TGA, thermogravimetric analysis [Color figure can be viewed at wileyonlinelibrary.com] between water absorption and square root of time in the first few days of hygrothermal aging, followed by saturation for both samples. This trend has already been reported for PHBV and polylactide (PLA) ${ }^{[26,35,38-40]}$. The water diffusion coefficients $(D)$ at $65^{\circ} \mathrm{C}$, obtained from the best fit of experimental data according to Equation (2), are similar and their values are estimated to $9.0 \times 10^{-7}$ and $9.3 \times 10^{-7} \mathrm{~cm}^{2} \mathrm{~h}^{-1}$ for Cast PHBV and CPHBV/3C30B bionanocomposite, respectively. The literature ${ }^{[38,41-42]}$ reported that the capacity of water absorption and its rate of diffusion in nanocomposites depending on various factors such as: specific surface area of the clay, micro vide existing in the polymer/clays interfaces, free volume in polymer matrix, the tortuosity of water diffusion into the polymeric matrix, molecular relaxation and polymer matrix crystallinity. The higher amount of water absorption in the PHBV bionanocomposite is related to the hydrophilic nature of organoclays (C30B). Due to their polar hydroxyl groups $(\mathrm{OH}), \mathrm{C} 30 \mathrm{~B}$ may interact with the water molecules through hydrogen bonds resulting in the enhancement of wettability of PHBV. It should be also pointed out that beyond 60 days of exposure, the sample weight of both materials decreases, due to hydrolysis reactions as revealed by SEC and FT-IR analyses, and probable consecutive leaching of the samples.

\section{5 | Thermal properties changes}

Table 2 summarizes the values of the main thermal characteristics of neat PHBV, Cast PHBV and C-PHBV/3C30B bionanocomposite before and during the hygrothermal aging. Moreover, Figure 6 shows the DSC thermograms

T A B L E 3 Decomposition temperature values of neat PHBV, Cast PHBV and C-PHBV/3C30B bionanocomposite before and after exposure to hygrothermal aging $\left(100 \% \mathrm{RH}, 65^{\circ} \mathrm{C}\right)$

\begin{tabular}{|c|c|c|c|c|c|}
\hline Samples & Exposure time (days) & $T_{5 \%}\left({ }^{\circ} \mathrm{C}\right)$ & $T_{50 \%}\left({ }^{\circ} \mathrm{C}\right)$ & $T_{\max }$ rate $T_{\operatorname{mdr}}\left({ }^{\circ} \mathrm{C}\right)$ & Char $(\%)$ at $600\left({ }^{\circ} \mathrm{C}\right)$ \\
\hline \multirow[t]{2}{*}{ Neat PHBV } & 1 & 270 & 287 & 288 & 1.2 \\
\hline & 0 & 263 & 282 & 285 & 1.30 \\
\hline \multirow{2}{*}{ Cast PHBV } & 60 & 261 & 279 & 282 & 1.67 \\
\hline & 100 & 254 & 277 & 280 & 1.15 \\
\hline \multirow{3}{*}{ C-PHBV/3C30B } & 45 & 266 & 288 & 290 & 4.04 \\
\hline & 60 & 265 & 284 & 287 & 4.04 \\
\hline & 100 & 264 & 282 & 284 & 3.12 \\
\hline
\end{tabular}

Abbreviations: PHBV, poly(3-hydroxybutyrate-co-3-hydroxyvalerate); RH, relative humidity. 

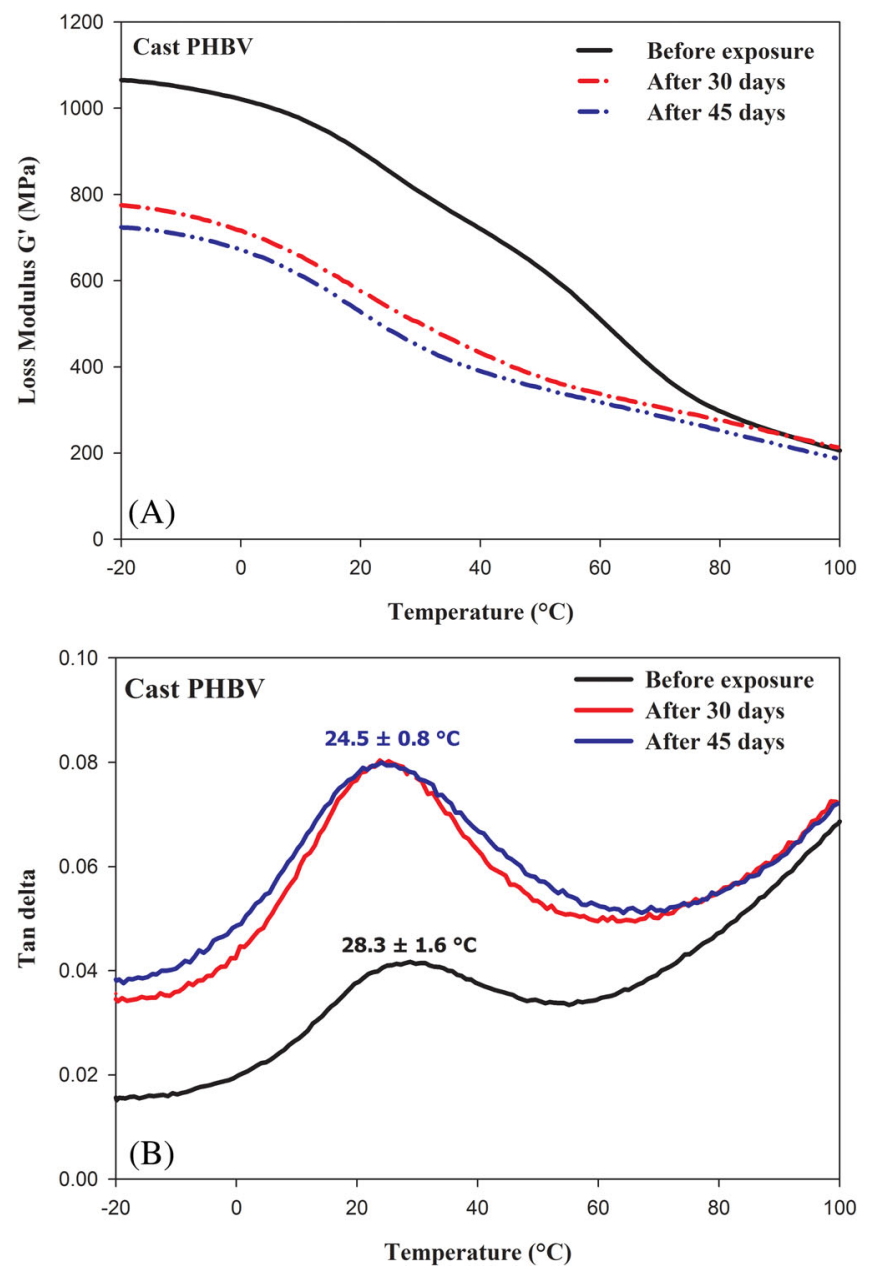

F I G U R E 9 Evolution of (A) storage modulus $\left(\mathrm{G}^{\prime}\right)$ and (B) loss factor (Tan $\delta$ ) for Cast PHBV at various exposure times to hygrothermal aging $\left(100 \% \mathrm{RH}, 65^{\circ} \mathrm{C}\right)$. PHBV, poly (3-hydroxybutyrate-co-3-hydroxyvalerate); [Color figure can be viewed at wileyonlinelibrary.com]

recorded during the second heating scans for aged samples at various exposure times.

Table 2 indicates a decrease in melting temperature $\left(T_{\mathrm{m}}\right)$ by a few degrees for Cast PHBV and C$\mathrm{PHBV} / 3 \mathrm{C} 30 \mathrm{~B}$ bionanocomposite with increasing exposure time. Furthermore, over 45 days, DSC thermograms in Figure 6 clearly show the appearance of double melting peaks for both samples, that is, the primary melting peak $\left(T_{\mathrm{m} 1}\right)$ and a secondary melting peak $\left(T_{\mathrm{m} 2}\right)$ that becomes predominant and appears at lower temperature. The literature ${ }^{[43-44]}$ reported that the double melting peak in biopolyesters may result from recrystallization process. The overall decrease in $T_{\mathrm{m}}$ is ascribed to the formation of short chain segments with lower molecular weight due to chain scission through hydrolysis, and the consecutive formation of imperfect crystals. Thus, the lower melting peaks correspond to imperfect crystallites formed after melting and recrystallization of
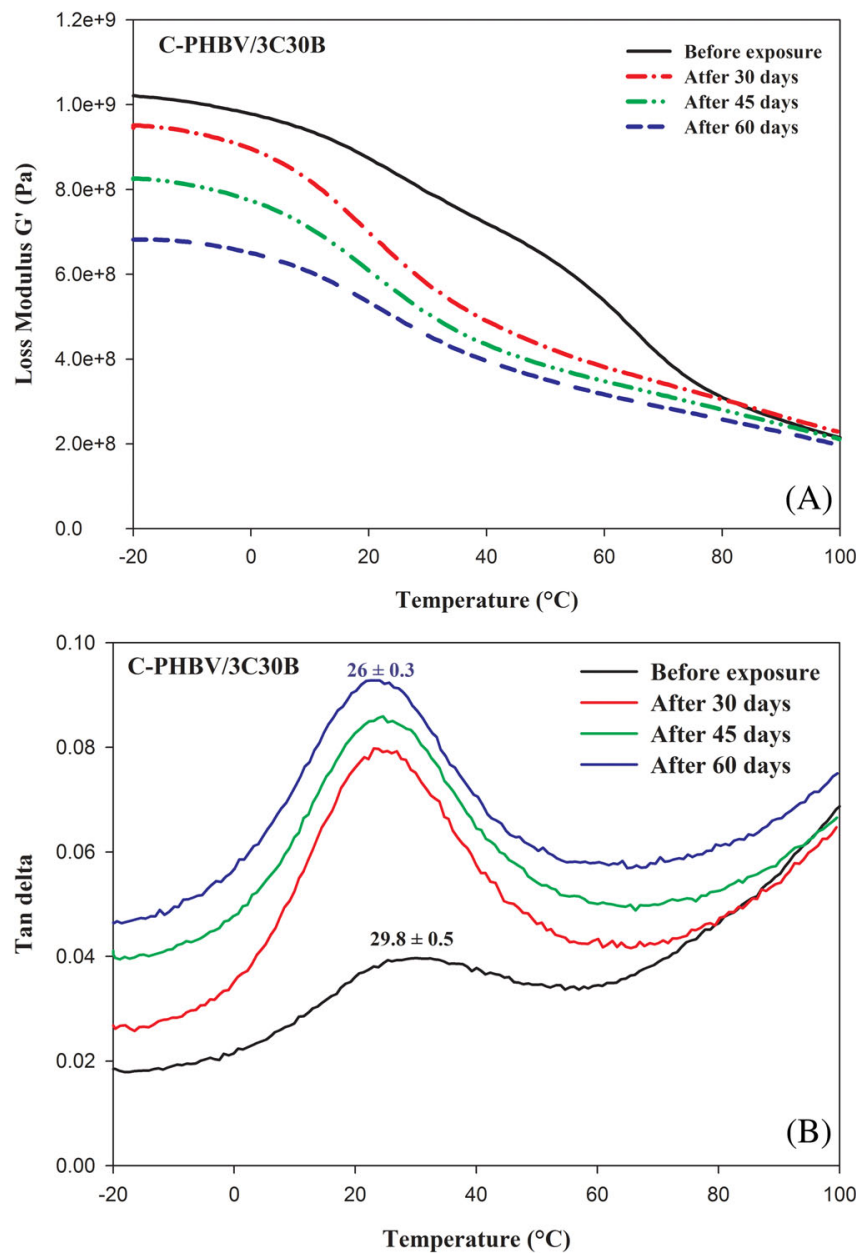

F I G U RE 10 Evolution of (A) storage modulus $\left(\mathrm{G}^{\prime}\right)$ and (B) loss factor (Tan $\delta$ ) for C-PHBV/3C30B nanocomposite at various exposure times to hygrothermal aging $\left(100 \% \mathrm{RH}, 65^{\circ} \mathrm{C}\right)$. PHBV, poly(3-hydroxybutyrate-co-3-hydroxyvalerate); [Color figure can be viewed at wileyonlinelibrary.com]

aged samples, while the higher melting peaks correspond to more perfect crystals that melt at higher temperature ${ }^{[42,45]}$. Table 2 also shows a slight decrease of $T_{\mathrm{c}}$ and $X_{\mathrm{c}}$ with increasing exposure time. Indeed after 100 days of exposure, $T_{\mathrm{c}}$ decreases by almost 6 and $2{ }^{\circ} \mathrm{C}$, and $X_{\mathrm{c}}$ decreases by almost $2 \%$ and $5 \%$ for Cast PHBV and C-PHBV/3C30B bionanocomposite, respectively. The decrease of $T_{\mathrm{c}}$ after aging can be related to reorganization of shorter macromolecular fragments in an order structure at lower temperatures. Whereas, the decrease of $X_{\mathrm{c}}$ results from the diffusion of water that restricts the recrystallization. Further, the large interfacial developed between the molecules of water and OMMT should reduce the mobility of the polymer chains ${ }^{[21,46]}$. On the other hand, a decrease in $T_{\mathrm{c}}, T_{\mathrm{m}}$, and $X_{\mathrm{c}}$ is observed between the neat and Cast PHBV, that should be the result of PHBV degradation during melt processing as shown in SEC experiments. 
T A B L E 4 Tensile properties changes of Cast PHBV and C-PHBV/C30B bionanocomposite before and after exposure to hygrothermal aging $\left(100 \% \mathrm{RH}, 65^{\circ} \mathrm{C}\right)$

\begin{tabular}{lcccc} 
Samples & Exposure time (h) & Young's modulus (MPa) & Tensile strength (MPa) & Elongation at break (\%) \\
\hline Cast PHBV & 0 & $1020 \pm 51$ & $27.0 \pm 1.4$ & $2.9 \pm 0.2$ \\
& 15 & $1070 \pm 61$ & $25.7 \pm 0.2$ & $3.0 \pm 0.3$ \\
& 30 & $741 \pm 58$ & $15.4 \pm 1.9$ & $2.6 \pm 0.4$ \\
& 45 & $681 \pm 73$ & $11.4 \pm 1.2$ & $2.0 \pm 0.4$ \\
& 60 & $657 \pm 56$ & $6.2 \pm 2.4$ & $2.4 \pm 0.8$ \\
C-PHBV/3C30B & 0 & $1180 \pm 42$ & $28.0 \pm 1.3$ & $3.9 \pm 0.1$ \\
& 15 & $1160 \pm 42$ & $31.7 \pm 3.0$ & $3.2 \pm 0.2$ \\
& 30 & $848 \pm 75$ & $24.7 \pm 2.0$ & $3.2 \pm 0.3$ \\
& 45 & $882 \pm 79$ & $19.3 \pm 4.0$ & $2.5 \pm 0.6$ \\
\end{tabular}

Abbreviations: PHBV, poly(3-hydroxybutyrate-co-3-hydroxyvalerate); RH, relative humidity.

\section{6 | Thermal stability}

TGA and DTG thermograms for neat PHBV, Cast PHBV, and $\mathrm{C}-\mathrm{PHBV} / 3 \mathrm{C} 30 \mathrm{~B}$ bionanocomposites as function of exposure time are shown in Figures 7(A), (B) and 8(A), (B), respectively. The values of degradation temperatures are presented in Table 3.

Before hygrothermal aging, Cast PHBV exhibits onestep decomposition with a weight loss between 260 and $290^{\circ} \mathrm{C}$. The DTG curves also display a minimum at roughly $285^{\circ} \mathrm{C}$ associated with the temperature at maximum degradation rate, as shown in Figure 7(B). The results indicate also that the thermal stability of neat PHBV is reduced after processing due to the decrease in the molar mass as shown by SEC data.

The bionanocomposite C-PHBV/3C30B also shows a one-step decomposition with a temperature at maximum degradation rate at around $293^{\circ} \mathrm{C}$ (Figure 8(B)), hence higher than non-aged Cast PHBV. The enhancement of thermal stability with addition of organoclay C30B in PHBV is attributed to the tortuosity phenomena which restricts the diffusion of oxygen, thus reducing the rate of decomposition ${ }^{[47]}$. After hygrothermal exposure, the decomposition temperatures for both samples decrease with increasing the exposure time.

Table 3 shows that after 100 days, $T_{5 \%}$ and $T_{\mathrm{mdr}}$ decrease by 9 and $5^{\circ} \mathrm{C}$ for Cast PHBV, respectively. For the bionanocomposite material, $T_{5 \%}$ and $T_{\mathrm{mdr}}$ also shifted to lower values with a decrease by 2 and $9^{\circ} \mathrm{C}$, respectively. The decrease of thermal stability may be due to the effects of both thermal and hydrolytic degradation. It should be pointed out that the bionanocomposite exhibited the better thermal stability compared to neat PHBV even at 100 days of aging.

\subsection{Viscoelastic properties changes}

Dynamic mechanical measurements were performed to examine the effect of hygrothermal aging on the viscoelastic properties of Cast PHBV and PHBV/C30B bionanocomposite samples. Figures $9(\mathrm{~A}),(\mathrm{B})$ and 10 (A), (B) show the evolution of storage modulus $\left(\mathrm{G}^{\prime}\right)$ and loss factor $(\tan \delta$ ) with exposure time for aged samples, respectively. Before exposure to hygrothermal aging, it is noticed that the storage modulus $\left(G^{\prime}\right)$ of the bionanocomposite is higher than that of Cast PHBV. Indeed at $20^{\circ} \mathrm{C}$, the value of $\mathrm{G}^{\prime}$ is roughly 896 and $1021 \mathrm{MPa}$ for Cast PHBV and C-PHBV/3C30B bionanocomposite, respectively. It is also observed that $\tan \delta$ shifts toward a higher temperature for the bionanocomposite. Tan $\delta$ of Cast PHBV is located almost at $28.3 \pm 1.6^{\circ} \mathrm{C}$ which increases very slightly to $29.8 \pm 0.5^{\circ} \mathrm{C}$ for $\mathrm{C}-\mathrm{PHBV} / 3 \mathrm{C} 30 \mathrm{~B}$ bionanocomposite. The improvement of $\mathrm{G}^{\prime}$ and to a less extent of $\alpha$-transition temperature is due to a good dispersion of $\mathrm{C} 30 \mathrm{~B}$ and also to its interactions with the polymer matrix restricting the macromolecular chains mobility. After exposure to hygrothermal aging, the storage modulus is significantly reduced for both aged samples with time. In addition, C-PHBV/3C 30B bionanocomposite is less affected by hydrothermal aging compared with Cast PHBV; Indeed, after 45 days of exposure at $20^{\circ} \mathrm{C}$, $\mathrm{G}^{\prime}$ of Cast PHBV decreases by almost $42 \%$ with respect to that of unexposed sample, whereas for the bionanocomposite, $\mathrm{G}^{\prime}$ is reduced by about $23 \%$ after 60 days. Above 45 and 60 days of aging, Cast PHBV and $\mathrm{C}-\mathrm{PHBV} / 3 \mathrm{C} 30 \mathrm{~B}$ were very brittle to be tested. From Figures 9(B) and 10(B), it can be seen that the shape of $\operatorname{Tan} \delta$ signals indicates a shift in the $\alpha$-transition temperature toward lower temperatures 
for both samples as well as a significant increase in Tan $\delta$ magnitude. Indeed, after 60 days of exposure, the Cast PHBV and bionanocomposite exhibit an $\alpha$-transition at $28.3 \pm 1.6$ and $29.8 \pm 0.5^{\circ} \mathrm{C}$, which slightly decreases to $24.5 \pm 0.8$ and $26.0 \pm 0.3^{\circ} \mathrm{C}$, respectively. This increased damping and earlier activated molecular motion of the aged samples, revealed by the higher Tan $\delta$ and lower $\alpha$-transition temperature respectively, is due likely to the decrease in the molar mass resulting from the hydrolytic degradation of PHBV.

\section{8 | Tensile properties changes}

The results of tensile properties of aged samples are summarized in Table 4. It is observed that Young's modulus, tensile strength, and elongation at break for Cast PHBV are reduced along hygrothermal aging.

After 60 days of exposure, the values for Young's modulus, tensile strength and elongation at break are decreased by $36 \%, 77 \%$, and $52 \%$, respectively, as compared to nonaged PHBV. In addition, the samples are too brittle and cannot be tested. According to the literature [33-34], the decrease in Young's modulus and strength of PHBV during aging is attributed to the decrease of molar mass. Furthermore, the mechanical properties of the bionanocomposite are less altered compared with Cast PHBV. Indeed, Young's modulus, tensile strength and elongation at break were reduced by $25 \%, 47 \%$, and $5 \%$, respectively. Accordingly, the incorporation of $\mathrm{C} 30 \mathrm{~B}$ in PHBV counterbalances the detrimental effects of aging on the tensile properties of the PHBV bionanocomposite.

\section{4 | CONCLUSION}

The effect of hygrothermal aging at $65^{\circ} \mathrm{C}$ and $100 \% \mathrm{RH}$ on neat PHBV and its bionanocomposite C-PHBV/C30B was investigated up to 100 days. It can be concluded that the incorporation of $\mathrm{C} 30 \mathrm{~B}$ into PHBV matrix increased the water absorption. The aged materials exhibited a strong modification on the chemical structure. Indeed, the carbonyl intensity index decreased during degradation, attesting for a hydrolysis phenomenon upon aging. However, the extent of decrease in the carbonyl intensity index was lower for the C-PHBV/3C30B bionanocomposite. Hydrolysis process via chain scission mechanism leads to a decrease in the molecular mass of both Cast PHBV and bionanocomposite, being however, less pronounced for the latter. Melting and crystallization temperature as well as the degree of crystallinity decreased with increasing exposure times. Thermal stability of aged Cast PHBV and aged C-PHBV/3C30B were reduced but remained higher for the bionanocomposite. Tensile and viscoelastic properties of PHBV were significantly affected by aging, whereas these properties were more stable for the bionanocomposite. The study revealed that the dispersion of C30B in PHBV allows to improve its hygrothermal stability and better maintained its physical and mechanical properties up to 60 days. These findings can be of interest for applications where functional properties of PHBV should be retained for a while in hygrothermal conditions at $65^{\circ} \mathrm{C}$ and $100 \%$ RH.

\section{ACKNOWLEDGMENTS}

The study was supported by Erasmus Mundus European program (Averroes 4). The technical assistance in the SEC analysis by Jean Coudane and Sylvie Hunger are gratefully acknowledged.

\section{ORCID}

Kahina Iggui (1) https://orcid.org/0000-0001-8353-8292 Mustapha Kaci (D) https://orcid.org/0000-0002-4283-9803 Nicolas Le Moigne (1) https://orcid.org/0000-0002-12187090

Anne Bergeret (iD https://orcid.org/0000-0001-7118-6584

\section{REFERENCES}

[1] A. L. Rivera-Briso, Á. Serrano-Aroca, Polymers (Basel) 2018, $10,732$.

[2] Z. Li, J. Yang, X. J. Loh, NPG Asia Mater 2016, 8, 265.

[3] Y. Li, T. J. Strathmann, Green Chem 2019, 21, 5586.

[4] E. Bugnicourt, P. Cinelli, A. Lazzeri, V. Alvarez, Express Polym Lett 2014, 8, 791.

[5] H. Liu, Z. Gao, X. Hu, Z. Wang, T. Su, L. Yang, S. Yan, J Polym Environ 2017, 25, 156.

[6] F. Massod, M. Aziz, H. Haider, Int Biodeterior Biodegdation 2018, 126, 1.

[7] Y. Phua, W. S. Chow, I. Mohd, J Thermoplast Compos Mater 2010, 14, 133.

[8] L. Zaidi, S. Bruzaud, A. Bourmaud, P. Médéric, M. Kaci, J Appl Polym Sci 2010, 116, 1357.

[9] J. K. Pandey, K. Raghunatha Reddy, A. Pratheep Kumar, R. P. Singh, Polym Degrad Stab 2005, 88, 234.

[10] S. Slater, D. Glassner, E. Vink, T. Gerngross, in Biopolym Online, Vol. 10 (Ed: A. Steinbüchel) 2006, p. 474.

[11] V. M. Correlo, E. D. Pinhp, I. Pashkuleva, M. Bhattacharya, N. M. Neves, R. L. Reis, Macromol Biosci 2007, 7, 354.

[12] W. S. Chow, A. Abu Bakar, Z. A. Mohd Ishak, J Appl Polym Sci 2005, 98, 780.

[13] H. Chen, F. Chen-Xia, W. B. Zhang, J. H. Yang, T. Huang, N. Zhang, Y. Wang, Polym Degrad Stab 2013, 98, 198.

[14] H. M. Chen, Y. P. Wang, J. Chen, J. H. yang, N. Zhang, T. Huang, Polym Degrad Stab 2013, 98, 2672.

[15] Z. A. Mohd Ishak, J. P. Berry, J Appl Polym Sci 1994, 51, 2145.

[16] G. Gorrasi, R. Pantani, Polym Degrad Stab 2013, 98, 1006. 
[17] A. V. Janorkar, A. T. Metters, D. E. Hirt, Macromolecules 2004, 37(24), 9151.

[18] O. Gil-Castell, J. D. Badia, T. Kittikorn, E. Stromberg, A. Martinez-Felipa, M. EK, S. Karlsson, A. Ribes-Greus, Polym Degrad Stab 2014, 108, 212.

[19] J. D. Badia, I. Santonja-blasco, A. Martinez-Felipe, A. RibesGreus, Polym Degrad Stab 2012, 97, 1881.

[20] T. G. Volova, A. N. Boyandin, A. D. Vaselliv, V. A. Karpov, S. V. Prundmkova, O. V. Mishukova, Polym Degrad Stab 2010, 95, 2350.

[21] Y. Phua, W. S. Chow, Z. A. Mohd Ishak, Polym Degrad Stab 2011, 96, 1194.

[22] V. A. Zhuikov, Y. V. Zhuikova, T. K. Makhina, V. L. Myshkina, A. Rusakov, A. Useinov, V. V. Voinova, G. A. Bonartseva, A. A. Berlin, A. P. Bonartsev, A. L. Iordanskii, Polymers 2020, 12, 728.

[23] K. Mazur, S. Kuciel, Molecules 2019, 24, 3538.

[24] V. A. D. Marinho, L. H. Carvalho, E. L. Canedo, Am Instit Phys 2015. 1664, 060003. https://doi.org/10.1063/1.4918421.

[25] J. D. Badia, T. Kittikorn, E. Strömberg, L. Santonja-Blasco, A. Martínez-Felipe, A. Ribes-Greus, M. Ek, S. Karlsson, Polym Degrad Stab 2014, 108, 166.

[26] H. Ventura, J. Claramunt, M. A. Rodríguez- Pérez, M. Ardanuy, Polym Degrad Stab 2017, 142, 129.

[27] R. N. Silva, L. R. C. Silva, A. C. L. Morais, T. S. Barbosa, J Thermoplast Compo Mater 2019, 89270571985604. https:// doi.org/10.1177/0892705719856044.

[28] K. Iggui, N. Le Moigne, S. Cambe, J. R. Degorce-Dumas, M. Kaci, A. Bergeret, Polym Degrad Stab 2015, 119, 77.

[29] V. Berthé, L. Ferry, J. C. Bénézet, A. Bergeret, Polym Degrad Stab 2010, 95, 262.

[30] J. Crank, The mathematics of Diffusion, 2nd ed., Clarendon Press, Oxford 1975.

[31] F. Rosario, E. Corradini, S. A. Casarin, J. A. M. Agnelli, J Polym Environ 2013, 21, 789.

[32] P. J. Barham, A. Keller, E. L. Otun, P. A. Holmes, J Mater Sci 1984, 19, 2781.

[33] K. Iggui, M. Kaci, M. Mahlous, N. Le Moigne, A. Bergeret, J Renew Mater 2019, 7, 807.
[34] K. Iggui, M. Kaci, N. Le Moigne, A. Bergeret, J Renew Mater 2018, 6, 288.

[35] M. Deroiné, A. Le Duigou, Y. M. Corre, P. Y. Le Gac, P. Davies, G. César, S. Bruzaud, Polym Degrad Stab 2014, 105, 237.

[36] I. Zembouai, M. Kaci, S. Bruzaud, L. Dumazert, A. Bourmaud, Polym Test 2016, 49, 29.

[37] I. Zembouai, M. Kaci, S. Bruzaud, I. Pillin, J. L. Audic, Polym Degrad Stab 2016, 132, 117.

[38] C. Y. Tang, D. Z. Chen, T. M. Yue, K. C. Chan, C. P. Tsui, P. H. F. Yu, Compos Sci Technol 2008, 68, 1927.

[39] A. Le Duigou, P. Davies, C. Baley, Polym Degrad Stab 2009, 94, 1151.

[40] M. Deroiné, A. Le Duigou, Y. M. Corre, P. Y. Le Gac, P. Davies, G. César, S. Bruzaud, Polym Degrad Stab 2014, 108, 319.

[41] B. Harintharavimal, H. Azman, I. Muhammad, W. Mat Uzir, J Polym Environ 2011, 19, 863.

[42] T. Aouat, M. Kaci, J. M. Lopez-Cuesta, E. Devaux, Front Mater 2019, 6, 323.

[43] L. Santonja-Blasco, A. Ribes-Greus, R. G. Alamo, Polym Degrad Stab 2013, 98, 771.

[44] Y. Shieh, G. Liu, J Polym Sci Part B Polym Phys 2007, 45, 466.

[45] M. Ma, W. Zhou, Ind Eng Chem Res 2015, 54, 2599.

[46] S. S. Ray, M. Bousmina, K. Okamoto, Macromol Mater Eng 2005, 290, 759.

[47] L. Zaidi, M. Kaci, S. Bruzaud, A. Bourmaud, Y. Grohens, Polym Degrad Stab 2010, 95, 1751. 